\title{
Medical Professionalism in the U.S.: Under Vigorous Challenge by International medical graduate committee of gap
}

\author{
Milton Kramer ${ }^{*}$, Mantosh Dewan, Antony Fernandez, Rama Rao Gogineni, Jeffrey Goldberg, \\ Hesham Hamoda, Ramotse Saunders, Andres Sciolla, Jacob Sperber and Nyapati Rao
}

University of Cincinnati, New York, USA

\begin{abstract}
The values of American culture have changed and this has led since 1970 to a competition with traditional medical values. The social forces that have stirred a reconsideration of core medical values come from 1 . economic, 2 . institutional and 3. life style sources and is related to efforts by non-service providers to gain profits from medical services and the attempts by both governmental and non-governmental sources to control the cost of medical care.

The actions of physicians will be assessed based on how well their behavior conforms to the ethical precepts of the profession. Being instructed in what the ethical precepts are and in how they were derived should contribute to establishing the expectations for what is expected of the physician. In order to delineate medical professionalism for the practitioner and the student we will explore:

1) the sources from which medical professionalism were derived,

2) the attempts to define medical professionalism,

3) conceptual approaches to medical professionalism,

4) the process of change in the scope of medical professionalism in the $20^{\text {th }}$ century, and

5) attempts to teach medical professionalism.

The intrusion of cost into medical care has been the key challenge to professionalism.
\end{abstract}

Keywords: Medical professionalism, history professionalism, challenges.

\section{INTRODUCTION}

The ethics of medicine are being challenged by the changes in the social milieu that are currently occurring in this period of deprofessionalization under economic, institutional and life style pressures [1]. The current turmoil has been dated to about 1970 and attributed to the rise of consumerism, cost control devices such as Health Maintenance Organizations [HMO], medicine becoming a profit center and converting doctors into hourly employees with the consequent life-style changes.

Essential to the behavior of physicians as well as those in training to become physicians is to understand the source and traditional concept of medical ethics which is currently being challenged. These are the standards on which their medical activity will be judged and to which one hopes they will aspire. The present essay will review: 1] the history of medical professionalism, 2] the extent and complexity of attempts to define medical professionalism, 3] conceptual

*Address correspondence to this author at 168 W. 86 St., Apt.6C, New York, NY 10024, USA; Tel: 212-362-4881;

E-mail: Milton1929@yahoo.com approaches to professionalism, 4] the development of professionalism in the $20^{\text {th }}$ century, and 5] educational attempts to teach medical professionalism.

\section{THE HISTORY OF MEDICAL PROFESSIONALISM}

The essence of medical professionalism is that medicine like the ministry is a calling not just a vocation [2]. It is an activity of service to others in which the needs of those to be served preempt the needs of the service provider. The doctor patient bond creates a fiduciary relationship at its core. Imber in "Trusting Doctors: The Decline of Moral Authority in American Medicine [3]" notes that American medicine was legitimated through an alliance with Protestant clergy in the $19^{\text {th }}$ century and shared missionary work with them thereafter. This early alliance buttressed the standing of medicine as a "sacred vocation" committed to altruism, virtuous living, and priestly comportment. Science was necessary but not the whole story; medicine sought spiritual and physical wellbeing as well. Medicine then parted ways with Protestantism over Darwin, the Scopes trial and the Victorian debate over intercessory prayers. The Catholic contribution to medical professionalism was through casuistry i.e. the importance of right thinking-in specific cases founded on principled church doctrine, an argument by analogy. 
The position of the physician within American society has changed enormously over the last 300 years. In prerevolutionary America physicians were not graduates of medical schools, there weren't any, and if prepared at all had been as an apprentice to a self-declared physician. A few doctors had gone to Europe and gotten their degree from a European medical school. Doctors were held in very low regard as what they could offer as treatment was so ineffective. The Jacksonian era motto "Each man his own doctor" captures the public's view of physicians at the time. The major change in the public's view of physicians came with the successful building of the Panama Canal (1914) as doctors were able to control the devastation of yellow fever. It became clear they had something to offer and the Jacksonian motto changed to "Doctors know best".

There had been the aggressive development of medical schools in the United States in the latter part of the $19^{\text {th }}$ and early $20^{\text {th }}$ century the quality of which was of some concern. Abraham Flexner [4], an educator, had been commissioned by the Carnegie Foundation to evaluate the quality of the large number of medical schools, 155 that existed. He visited them all and wrote a devastatingly critical report in 1910 that encouraged many, especially the large number of proprietary ones, be closed and that medical colleges become part of universities and more scientifically focused, which they did, but concomitantly they became less humanistic. Johns Hopkins was the model Flexner used. It was during the next 50 years that medicine took control of the education, organization, delivery and regulation of health care providers in the US.

American medicine has looked historically to the Oath of Hippocrates $\left(5^{\text {th }}\right.$ Century B.C.E.) to provide the foundation for the ethical practice of medicine. The Oath sets a platform for the practice of medicine. The Oath of Hippocrates was not written by him but by an unknown person a century after his death. The ongoing references to the Oath reflects its continuing importance as an ethical standard.

\footnotetext{
Hippocratic Oath Classical Version [5]

I swear by Apollo, the healer, Asclepius, Hygeia, and Panacea, and I take to witness all the gods, all the goddesses, to keep according to my ability and my judgment, the following Oath and agreement:

To consider dear to me, as my parents, him who taught me this art; to live in common with him and, if necessary, to share my goods with him; To look upon his children as my own brothers, to teach them this art.

I will prescribe regimens for the good of my patients according to my ability and my judgment and never do harm to anyone.

I will not give a lethal drug to anyone if I am asked, nor will I advise such a plan; and similarly I will not give a woman a pessary to cause an abortion.

But I will preserve the purity of my life and my arts.

I will not cut for stone, even for patients in whom the disease is manifest; I will leave this operation to be performed by practitioners, specialists in this art.

In every house where I come I will enter only for the good of my patients, keeping myself far from all intentional ill-doing and all seduction and especially from the pleasures of love with women or with men, be they free or slaves.

All that may come to my knowledge in the exercise of my profession or in daily commerce with men, which ought not to be spread abroad, I will keep secret and will never reveal.

If I keep this oath faithfully, may I enjoy my life and practice my art,
}

respected by all men and in all times; but if I swerve from it or violate it, may the reverse be my lot.

Roberts and Dyer [6] have provided us with an examination of the Hippocratic oath that illustrates its connection to modern concepts espoused in current ethical codes.

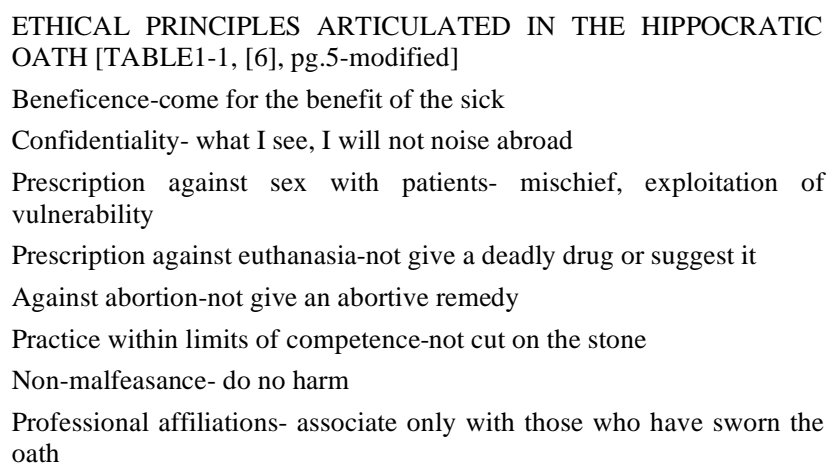

Prescription against sex with patients- mischief, exploitation of vulnerability

Prescription against euthanasia-not give a deadly drug or suggest it

Against abortion-not give an abortive remedy

Practice within limits of competence-not cut on the stone

Non-malfeasance- do no harm

Professional affiliations- associate only with those who have sworn the oath

There are many other medical oaths that reflect the values of other cultures. A cross-cultural comparison of medical oaths goes beyond the current undertaking [7]. However, there are significant cultural differences between how those physicians who come from collectivist countries view their ethical precepts compared to the more individualistic U.S. ethical principles. Foreign physicians are likely to be more authoritarian and paternalistic with less regard for privacy and confidentiality but to have more tolerance for emotionality than U.S. physicians.

The beginning of modern ethical codification is found in the work undertaken by Thomas Percival at the request of the board of the Manchester Royal Infirmary to deal with inter-professional problems [8]. He included issues related to how a physician should relate to patients. Percival published his work as a Code of Medical Ethics in 1803. The American Medical Association at its founding meeting used Percival's Medical Ethics as a basis for its first code of ethics in 1847, quoting sections directly from it. The AMA code was revised in 1903,1957, 1980 and 2001. The changes are responsive to the changing social conditions in the U.S. In 1847 the concern in part was with the dangers of secret and patent medicines and quack remedies. In 2011, the code, among other things, stated the physician should provide competent and compassionate care and recognize that responsibility to the patient is paramount. The physician must be honest and report physicians who are deficient in character or who engage in fraud. Charlatanism was an issue in 1847 and in 2011.

\section{THE EXTENT AND COMPLEXITY OF ATTEMPTS TO DEFINE MEDICAL PROFESSIONALISM}

The subject of our exploration is Medical professionalism and it would be helpful if we could by providing a definition 
delineate the arena for our efforts. There is unfortunately no universally held definition of Medical professionalism. An exploration of the various attempts to define it would be useful to provide an understanding of the thinking and concepts that surround Medical professionalism.

Roberts and Hoop [9], provide a listing of some definitional attempts: Being a professional is an ethical matter, entailing a devotion to a way of life in the service of others and for some higher good [10]. A profession is a socially sanctioned activity whose primary object is the wellbeing of others above the professional's gain [11]. A profession has three features: training that is intellectual and involves knowledge, as distinguished from skill; work that is pursued for others and not for oneself; and success that is measured by more than the financial return [12]. Professionalism is not a matter of trying but of being [13]. A profession is a set of values, attitudes, and behaviors that result in serving the interests of patients and society before one's own [14]. Professionalism means aspiring to altruism, accountability, excellence, duty, service, honor, integrity, and respect for others [15].

Atul Gawande [2] is of the opinion that all learned occupations have a definition of professionalism...where they spell out their ideals and duties... they all have three common elements. He offers them succinctly. First is an expectation of selflessness: that we who accept responsibility for others... will place the needs and concerns of those who depend on us above our own. Second is an expectation of skill; that we will aim for excellence in our knowledge and expertise. Third is an expectation of trustworthiness: that we will be responsible in our personal behavior toward our charges. Aviators hold up a fourth one discipline, autonomy opposes it; it is attention to detail, like in checklists. Groopman opposes checklist as too inhibiting.

In a series of articles, Ethics in Medicine [16], from the University of Washington School of Medicine, the authors point out that the word profession comes from the Latin "profession" which means a public declaration with the force of a promise [Perhaps calling attention for us to reconsider the value of an oath on our entry into the profession]. Professions are groups, which declare in a public way that their members promise to behave in certain ways and that the society may discipline those who fail to do so. The profession presents itself to society as a social benefit and society accepts the profession, expecting it to serve some important social good.

The hall marks of a profession they believe [16] are: 1 . Competence in a specialized body of knowledge and skill; 2 . An acknowledgment of specific duties and responsibilities toward the individual it serves and toward society; and 3. The right to train, admit, discipline and dismiss its members for failure to sustain competence or observe the duties and responsibilities. The crucial difference from a business is that professionals have a fiduciary duty toward those they serve. And, a code of ethics derives from their fiduciary duty. Professional obligations include: 1. Altruism; 2. Accountability-to patient, society, public health and the profession; 3. Excellence- lifelong learning; 4. Duty- available and responsive; 5. Honor and integrity-fair, truthful, straightforward with patient and profession; and 6 . Respect for others-patient, their families, students, and coworkers.

Given the discursive statements about Medical professionalism that has been explored so far a need for an embracing definitional attempt is clear. Swick [17] has recommended that if we are to have a meaningful discussion of professionalism, a normative definition, which is grounded in what physicians actually do individually and collectively, would be useful. He then offers a nine-point definition with elaboration of each point:

1. Physicians subordinate their own interests to the interests of others and are patient advocates.

2. Physicians adhere both personally and professionally to high ethical and moral standards doing right (beneficence) and avoiding wrong (non-malfeasance).

3. Physicians respond to societal needs, and their behaviors reflect a social contract with the communities served.

4. Physicians evince core humanistic values including honesty, integrity, caring and compassion, altruism and empathy, respect for others and trustworthiness.

5. Physicians exercise accountability for themselves and their colleagues.

6. Physicians demonstrate a continuing commitment to excellence by the continuing acquisition of knowledge, attitude and new skills and accepting ones limitations, an internal focus.

7. Physicians exhibit a commitment to scholarship and advancing their field, an external focus.

8. Physicians deal with high levels of complexity and uncertainty and must be able to make independent judgments and decisions in the face of complexity, unstable circumstances and with incomplete information.

9. Physicians must be able to reflect dispassionately and critically upon decisions made and actions taken.

It becomes apparent from survey studies [18-20] that physicians accept the precepts of Medical professionalism that are put forth but have considerable difficulty living up to them. Campbell et al. [18] found in a survey of 3,504 practicing physicians in the U.S. that most physicians agreed with professional principles regarding fair distribution of resources, access to and quality of care, conflicts of interest, and self-regulation that were proposed by professional societies in 2002. However, self-reported behaviors showed that about half did not follow self-regulation principles and a third would order unneeded MRI imaging for back pain in response to a patient's request. Having a normative description of professionalism serves to provide a baseline from which physicians deviate, rather than just a model of physician behavior.

Another example of deviance from ethical standards is the report by DesRoches, et al. [19] that in the self-regulation 
aspect of medical professionalism, physicians support the professional commitment to report all instances of impaired or incompetent colleagues in their medical practice to a relevant authority, but when faced with that situation many do not. Under-represented minorities and graduates of nonUS medical schools were less likely to make a report. The reasons given were "others taking care of it", "nothing would happen", and "the fear of retaliation".

Roland, M. et al. [20] addresses the level of commitment to ethical standards in a study in which they reported the results of a survey of about 3,000 physicians. They found that "eight of 10 strongly agreed that they should put patient welfare before their own financial interests." And, "four of 10 did not think they needed to inform their patients about any financial conflicts of interest with pharmaceutical companies. "The survey" included results from a survey of nearly 2,000 doctors in the United States and more than 1,000 in the United Kingdom."

It is interesting to note that state medical boards have a very low number of sanctions of physicians, 5,721 total in 2009 (0.9\% of all physicians) [21]. Public Citizen reports that physicians who are sanctioned by their own hospital board are rarely if ever reported to the state medical board [22].

\section{CONCEPTUAL APPROACHES TO PROFESSIONALISM}

\section{Introduction}

Roberts and Dyer [6] in a very focused and useful manner summarize a number of conceptual approaches to professionalism. They point out there are six principles on which health professionals can make complex ethical decisions, namely: beneficence, autonomy, nonmalfeasance, justice, veracity and fidelity [23]. It is striking that fiduciary is not included as fidelity is not really fiduciary. They also provide an updated version of the Charter on Medical Professionalism developed by several societies of internists [Board, College, and Society]. The Charter says in its preamble professionalism is the basis for medicines contract with society. It demands placing the patient's interests above those of the physician's, setting and maintaining standards of competence and integrity and providing expert advice on health issues to society. Public trust depends on the integrity of all physicians and the profession. The fundamental principles are 1] the primacy of patient welfare, 2] patient autonomy and 3] social justice. The professional responsibilities include commitment to professional competence, honesty with patients, patient confidentiality, maintaining appropriate relations with patients, improving quality of care, improving access to care, to scientific knowledge, maintaining trust by managing conflicts of interest to professional responsibilities

Davidoff [24] has seven key principles for health care professionals: 1.] Rights-people have a right to health and health care, 2.] Balance-patients central, but populations also, 3.] Co-operation-health care succeeds only if we cooperate with those we serve, each other and those in other sectors, 4.] Comprehensiveness-treat illness and ease suffering, minimize disability, prevent disease and promote health, 5.] Improvement- improving health care is a serious and continuing responsibility, 6.] Safety-do no harm, and 7.] Openness-open, honest and trustworthy. The reference to the right to health care opens an important moral dimension, which has surfaced with the passing of the Affordable [Health] Care Act in 2010.

\section{Principles, Rules Contextualism and Virtue [6]}

Principal based ethics are called teleological and emphasize outcomes and intent (tends to be more ambiguous when applied). Rule based ethics are called deontological ethics and emphasize prior imperatives as determining choice in ethical dilemmas (tends to offer a clarity and certainty), like laws. Contextualism holds that the rightness of a decision depends on the context. Casuistry examines the situation; all relevant principles, rules, history and meaning one may or ought to do. Virtue based ethics emphasizes the qualities of the moral agent evaluating and enacting a choice.

\section{Models of Ethical Thinking [6]}

These models of ethical thinking provide a link to the philosophical approaches that are the intellectual sources for explorations of moral thinking and ethical injunctions. Medical professionalism is a particularization that is often derived from these sources. The models that Roberts and Dyer [6] offer for consideration include:

1. Utilitarianism, ethic of consequences-John Stuart Mill-Weigh the consequences of actions and rules. The greatest good for the largest number are most ethical. Beneficence is goal.

2. Deontology-the ethics of duty-Imanuel Kant-There is an absolute good and right, to be ethical fulfill these duties unconditionally. Respect for person.

3. Casuistry or case ethics-Albert Jonsen- Take specific circumstances into account, reason by analogy from similar cases. Emphasis on context and precedent. Do not need a principle.

4. Care ethics-Carol Gilligan- Focus on care, responsibility and trust in relationships. Commitment is to others rather than to individual autonomy is basis for an ethical life. Emphasis is relationship and emotion, not principle and reason.

5. Virtue ethics- Edmund Pellegrino and David Thomasma- ethical decisions are rooted in qualities of character, actions are right if it is what a virtuous person would do, importance of motives and character.

6. Principle based ethics-Thomas Beauchamp and James Childress- General principles and rules are primary in making ethical decisions, method to resolve conflict.

\section{THE DEVELOPMENT OF PROFESSIONALISM IN THE $20^{\text {TH }}$ CENTURY}

\section{Phases of Medical Professionalism}

The modern story of professionalism [25] in American Medicine from a sociologic viewpoint begins in the early 
$20^{\text {th }}$ Century with Carr-Saunders and Wilson's The Profession (1933-1964) [26]. During this period began reform and the initial rise of organized medicine, which grew scientifically and technically and in status and legitimacy [27].

The Second phase [1940-1960's] was a phase of professional dominance [see Friedson's Professional Dominance [28] and Profession of Medicine [29] during which control of the production of knowledge, a division of labor, regulation of the provision of health services, and control of the health system took place. Medicine was seen as valuable and needed no regulation.

The Third phase [1970-present] is one of deprofessionalization [1], prolitarianization, corporatization and industrialization [30]. The forces of decentralization were the result of the challenges of high medical costs, medicine becoming a cottage industry for corporate players, Medicare, Medicaid, managed care, treatment becoming a commodity i.e. a cost center, the rise of biotechnology so medicine could be monitored and the forces of consumerism. The increased focus on professionalism came out of the loss of vision and the crisis in medicine that started in 1970 [31]. Payers including insurers, employers, and the government wanted to reform medical practice for economic reasons and medicine was all too willing a victim of its own reform, a reform defined by outside forces. Institutional medicine has been described as a major impediment in individual physicians achieving professionalism [32]. We need to reestablish trust in the medical profession. Americans, don't trust institutions and never have since Andrew Jackson's time [33].

Pellegrino [1] sees deprofessionalism as not a new phenomenon; but one that occurs when we accommodate to the dominant culture and deny medicine's higher standards. In the past what has occurred is an infusion of a new moral sensitivity. Whether this will occur again cannot be predicted. The present turmoil has dimensions of previous ones; namely, temptations of self-interest, power, prestige, pride, profit and privilege. There are however two sources of unique conflict one societal and one ethical.

Some of the social factors that stand out in the present turmoil are the defection of physicians from medical ethics e.g. from Medicare fraud to conflicts of interest in research. Other social factors are our treating health care as a product abandoned to the market place with its competition, commercialization and profit making and to life style change with a focus on free time. We have begun using free market rhetoric to justify profit, competition and self-interest. The result is the physician as employee with loyalties divided between patient and employer; often pitted against the patient to control costs. Patients see physicians as interchangeable [34] as 75\% of in-patient medical patients at the University of Chicago Hospital did not know their doctors name but rated their care highly. Professional worth is measured in productivity.

Pellegrino [1] sees as unique to our times the erosion of professional ethics. An example is the denial of the historical credibility of the Hippocratic Oath. Moral skepticism that denies any stable moral truth is made worse by cultural diversity with its strong pull to moral relativism. He believes it is difficult to reverse this trend as it is seen as going back to an idealism that really never worked. The need is to establish that the practice of medicine is indeed something special whose values must be articulated, believed and fought for.

Rothman [35] sees the professional problems in Medicine as long standing and not all are the result of managed care. He includes problems with pharmaceutical companies as a prime illustration, urging active limitation on their involvement with physicians. He advocates active efforts to engage the problems. For example, professional societies should demand service to the vulnerable to achieve and maintain membership forming alliances with consumer groups; medical schools including the teaching of professionalism and advocacy skills, and expanding lobbying efforts to be less parochial.

\section{Current Ethical Systems}

It is apparent that there has been a shift in the belief and ethical systems that govern or reflect the behaviors of physicians $[18,20]$. Under the pressure of decentralization, physicians have begun to practice other types of professionalism from that favored by the medical power structure and referred to by Castellini and Hafferty [25] as nostalgic professionalism. They see professionalism as a way of organizing medical work to claim it is a profession. They delineated from the literature $10 \mathrm{key}$ aspects of medical work, focused on what physicians actually do as Swick [17] had suggested. These key aspects involved value orientations, beliefs, skills, and control positions. They included the following key aspects:

1. Autonomy- discretionary decision making; do your work the way you think it should be done.

2. Commercialism- application of business principles to medical practice-medical knowledge is a commodity.

3. Social justice- medicine as fairness.

4. Social contract- covenant with society, mutual obligations.

5. Altruism- welfare of patients before doctors.

6. Professional dominance- medicine controls organization, delivery, and payment of health care.

7. Technical competence- skills to diagnose and treat illness.

8. Interpersonal competence- communicate well with patients and others.

9. Lifestyle ethic- devaluation of work in relationship to family and personal life.

10. Personal morality-one's own belief system in contrast to that of medicine.

Castellini and Hafferty [25] found what they thought were seven clusters of different styles of professionalism and rank ordered the key aspects within each cluster. These clusters are listed below including the first two and last two 
of the ten key aspects for each cluster to facilitate comparisons among clusters:

1. Nostalgic- autonomy, altruism/life style, commercialism;

2. Unreflective [clinicians]- autonomy, interpersonal competence/ social justice, social contract;

3. Academic- altruism, interpersonal competence/social justice, commercialism;

4. Entrepreneurial- commercialism, autonomy/social justice, social contract;

5. Empirical [Researchers]-autonomy, technical competence/ interpersonal competence life style;

6. Life style- autonomy, lifestyle/social justice, professional dominance;

7. Activist- social justice, social contract/commercialism, professional dominance.

\section{EDUCATION FOR PROFESSIONALISM}

The content and goals of under graduate and graduate medical education are determined by their accrediting bodies'. The Liaison Commission for Medical Education [LCME] for medical schools and the Accreditation Council of Graduate Medical Education [ACGME] for residency education. The ACGME promulgated a list of General competencies in1999, one of which was labeled Professionalism. Doukas [36] points out that $2 / 3$ of all the competencies are related to humanism, ethics and professionalism. In 2004, the LCME linked its professional standards to those of the ACGME. The core competency for professionalism of the ACGME clearly reflects the view of the medical power elite that has been earlier referred to as Nostalgic. The ACGME competency is reproduced here:

\section{ACGME CORE COMPETENCY-GRADUATE MEDICAL EDUCATION [JANUARY 23, 2008]}

\section{Professionalism}

ACGME Common Program Requirements state that each residency and fellowship program must require its residents and fellows to obtain competence in Professionalism. It is necessary for programs to define the specific knowledge, skills, behaviors, and attitudes required, as well as provide educational experiences as needed in order for their residents and fellows to demonstrate competency in the area of Professionalism.

Professionalism requires residents/fellows to demonstrate a commitment to carrying out professional responsibilities and an adherence to ethical principles. Residents are expected to demonstrate: ability to document and communicate, teach, make ethical decisions, be aware of the larger context and system of health care, as well as the ability to call effectively on other resources in the system to provide optimal health care. Residents/fellows are expected to demonstrate:

- $\quad$ Compassion, integrity, and respect for others;

- Responsiveness to patient needs that supersedes selfinterest;
- $\quad$ Respect for patient privacy and autonomy;

- Accountability to patients, society and the profession;

- $\quad$ Sensitivity and responsiveness to a diverse patient population, including but not limited to diversity in gender, age, culture, race, religion, disabilities, and sexual orientation.

Program Improvement activities assure full integration of this and other competencies with learning and clinical care. To review several recommended evaluation methodologies, (see program).

Core Assessment Systems are essential to improving resident performance in this competency as well as the other competencies. To review an example of comprehensive core assessment system, which uses multiple methodologies and raters, (see program).

Key Components:

- Components Of Professional Behavior

- $\quad$ Ethical principles

- Cultural Sensitivity

- Common Program Requirements (effective 7/1/07) are available at the ACGME website. ACGME also has provided a Program Director's Guide to the Common Program Requirements that became effective 7/1/07.

Examples of Professionalism in Curricula:

- Goals and Objectives - Example (see program)

- Goals and Objectives - Example (see program)

- Goals and Objectives - Example (see program)

Examples of Professionalism Evaluation Tools:

- $\quad$ Evaluation of Competencies (generic competencies)

- Annual Evaluation Form with Competencies (use for promotion)

- Summary Evaluation Form with Competencies (use for graduation)

ACGME has provided a Reference List as well as documented several Approaches to Assessment of SystemsBased Practice.

The recognition that perhaps there have developed a number of different ethical cluster which are to some degree interactive as described above raises a serious question as to what should be taught; the complexity of the system with no effort to choose one over the others. Or, perhaps teach the complexity but then make the point of the preferred one and why. The choice for many might be the Nostalgic Cluster.

The teaching needs to be as experiential as possible with an opportunity to report, tell the story, and to reflect on the experience. The value of a course, whether lecture or seminar, is to provide in addition a vocabulary related to morals and ethical behavior [37]. Although the use of literature that describes illness has been recommended, it has 
not shown to be nor do we feel it is helpful [38]. The humanistic social sciences are intellectually interesting but do not necessarily foster the development of more humane feelings in thestudents $[39,40]$.

The course work in various forms should be continued through the four years and into the residency. It is in the clinical years that the medical student becomes increasingly cynical as influenced by the so-called hidden agenda [41]. The hidden agenda is what actually happens on the wards not what should happen and is the major influence on the student's professional values.

There is the need to provide role models of ethical physicians of the type one hopes to develop [41, 42] The structural system in which education takes place must be examined and the aspects that contribute to ethical conflicts identified and where possible eliminated. The assumption of the professional's clinical autonomy is challenged by the changing structure of health care institutions and the financing of those institutions" [43]. The extensive training program in professionalism at the University of Indiana College of Medicine is described by Inui et al. [33] and at the University of Maryland College of Medicine by Talbott [44].

\section{CONCLUSIONS}

Medical professionalism is difficult to define but historically there is a descriptive and conceptual commonality to medical professionalism derived from the Hippocratic Oath. It is apparent however that in the last 40 years there has been a serious challenge to the moral foundation of medical practice.

The sources of the challenge relate to the commercialization of medicine, the demands of consumerism, the society's wish to control the cost of medical care and the desire of younger physicians to lead a more balanced life style.

These decentralizing challenges have led to a significant realignment of the values, beliefs and behaviors of medical practitioners which have been tentatively described as one of seven work clusters: 1] Nostalgic, 2] Academic, 3] Empirical, 4] Entrepreneurial, 5] Lifestyle, 6] Unreflective and 7] Activist. The central ethical value in medicine has been the conception of the doctor-patient relationship as one in which a fiduciary relationship is said to exist and the "patient's needs come first". The Entrepreneurial and Lifestyle practice formats present the greatest challenge to this fundamental fiduciary belief and the Empirical does to some degree as well.

The explicit teaching of professionalism is now required for medical students and residents. The type of teaching is variable including lectures on ethics and small discussion groups with a focus on telling the story of an event and reflecting on its ethical implications. It seems that virtuous role models may have the greatest effect in shaping the trainee's ethical practice.

There is the recognition that both the formal and hidden medical curriculum needs to be attended to. The structure of our medical institutions may well be creating ethical conflicts that an individual cannot resolve and that need group attention.

\section{CONFLICT OF INTEREST}

The authors confirm that this article content has no conflict of interest.

\section{ACKNOWLEDGEMENTS}

Declared none.

\section{REFERENCES}

[1] Pellegrino E. Medical professionalism: Can it, should it survive? J Am Board Fam Med 2000; 13: 47-9.

[2] Gawande A. The Checklist Manifesto: How to Get Things Right. New York: Metropolitan Books 2009; pp. 182-3.

[3] Imber J. Trusting Doctors: The Decline of Moral Authority in American Medicine. Princeton, NJ: Princeton University Press 2008.

[4] Flexner A. Medical Education in the United States and Canada: A Report to the Carnegie Foundation, 1910.

[5] Edelstein L. The Hippocratic Oath: Text, Translation, and Interpretation. Baltimore: Johns Hopkins Press 1943.

[6] Roberts L, Dyer A. Concise Guide to Ethics in Mental Health. Washington, D.C.: American Psychiatric Publishing, Inc., 2004.

[7] Bhugra D., Malik A. Professionalism in Mental Healthcare: Experts, Expertise and Expectations. Cambridge: Cambridge University Press 2011.

[8] Percival T. Medical Ethics. Manchester: S. Russell, 1803.

[9] Roberts L, Hoop J. Professionalism and Ethics: Q and A Self-Study Guide for Mental Health Professionals. Washington D.C.: American Psychiatric Publishing, Inc., 2008.

[10] Kass L. Professing ethically. On the place of ethics in defining medicine. JAMA 1983; 249:1305-10.

[11] Racy J. Professionalism: sane and insane. J Clin Psychiatry 1990; 51: 138-40.

[12] Brandeis L. Business: A Profession. Boston: Hole, Cushman and Flint 1993.

[13] LaCombe M. On professionalism. Am J Med 1993; 94: 329.

[14] Reynolds P. Reaffirming professionalism through the education community. Ann Intern Med 1994; 120: 609-14.

[15] Stobo J, Blank L. American Board of Internal Medicine's Project Professionalism: Staying ahead of the wave. Am J Med 1994; 97 : $1-3$.

[16] Ethics in Medicine: University of Washington School of Medicine 2011. Available at: http://depts.washington.edu/bioethx

[17] Swick H. Toward a normative definition of medical professionalism. Acad Med 2000; 75: 612-6.

[18] Campbell E, Regan S, Gruen R, et al. Professionalism in medicine: results of a national survey of physicians. Ann Intern Med 2007; 147: 795-802.

[19] DesRoches C, Rao S, Fromson J, Birnbaum R, Iezzoni L, Voegeli. Physicians' perceptions, preparedness, and experiences related to impaired and incompetent colleagues. JAMA 2010; 304: 187-93.

[20] Roland M, Rao S, Sibbald B, et al. Professional values and reported behaviors of doctors in the USA and UK: Quantitative survey. BMJ Qual Saf 2011; doi:10.1136/bmjqs. 2010.048173.

[21] Chaudhry H. Report of the Federation of State Medical Boards. 2009.

[22] Levine A, Oshel R, Wolfe S State Medical Boards fail to discipline doctors with hospital actions against them. Public Citizen. Available at: http://www.citizen.org/hrg193705 [March 15, 2011].

[23] Beachamp T, Childress J. Principles of Biomedical Ethics. $5^{\text {th }}$ ed. New York: Oxford 2001.

[24] Davidoff F. Changing the subject: ethical principles for everyone in health care. Ann Intern Med 2000; 133: 386-9.

[25] Catellani B, Hafferty F. Chapter 1: The Complexities of Medical Professionalism: A Preliminary Investigation. In: Wear D, Aultman J, Eds. Professionalism in Medicine: Critical Perspectives. New York: Springer 2006.

[26] Carr-Saunders A, Wilson P. The Professions. London: F. Cass 1933-64 
[27] Starr P. The Social Transformation of American Medicine. New York: Harper Collins/Basic Books 1982.

[28] Friedson E. Professional Dominance. Chicago: Aldine 1970.

[29] Friedson E. Profession of Medicine. New York: Dodd Mead 1970.

[30] Relman A. Education to defend professional values in the new corporate age. Acad Med 1998; 73:1229-33.

[31] Brincat C. Chapter 11: How medical training mangles professionalism: The prolonged death of compassion. In: Wear D, Aultman J, Eds. Professionalism in Medicine: Critical Perspectives. New York: Springer, 2006.

[32] Lewis B. Chapter 8. Medical Professionals and the discourse of professionalism: Teaching implications. In: Wear D, Aultman J, Eds. Professionalism in Medicine: Critical Perspectives. New York: Springer 2006; p. 155.

[33] Inui T, Cottingham A, Frankel R, et al. Chapter 9. Educating for professionalism at Indiana University School of Medicine: Feet on the ground and fresh eyes In: Wear D, Aultman J, Eds. Professionalism in Medicine: Critical Perspectives. New York: Springer 2006.

[34] Arora V, Gangireddy S, Mehrota A, Ginde R, Tormey M, Meltzer D. Ability of hospitalized patients to identify their in hospital physicians. Arch Intern Med 2009; 169: 199-201.

[35] Rothman D. Medical professionalism-focusing on the real issues. N Engl J Med 2000; 342:1284-6.

[36] Doukas D. Chapter 3 Professionalism: Curriculum goals and meeting their challenges. In: Wear D, Aultman J, Eds. Professionalism in Medicine: Critical Perspectives. New York: Springer 2006.

[37] Self D, Wolinsky F, Baldwin D. The effect of teaching medical ethics on medical students' moral reasoning. Acad Med 1989; 64:755-9.
[38] Shapiro J, Morrison E, Boker J. Teaching empathy to first year medical students: Evaluation of an elective literature and medicine course. Educ Health 2004; 17: 73-84 [cited in Kao, A. and Reenan, J. Chapter12. Pg. 224, Wit is not enough. In: D. Wear and J. Aultman [Eds.] Professionalism in Medicine: Critical Perspectives. New York: Springer 2006].

[39] Rodenhauser P, Strickland M, Gambala C. Arts related activities across U.S. medical schools: A follow-up study. Teach Learn Med 2004; 16: 233-9 [cited in Kao, A. and Reenan, J. Chapter12. Pg. 224, Wit is not enough. In: D. Wear and J. Aultman [Eds.] Professionalism in Medicine: Critical Perspectives. New York: Springer, 2006].

[40] Ousager J, Johannessen H. Humanities in undergraduate medical education: a literature review. Acad Med 2010; 85: 988-98

[41] Coulehan J. Chapter 6. You say self-interest, I say altruism In: Wear D, Aultman J, Eds. Professionalism in Medicine: Critical Perspectives. New York: Springer 2006; pp. 106-8, 110-1.

[42] Barry D, Cyran E, Anderson R. Common issues in medical professionalism: Room to grow. Am J Med 2000; 108: 136-42. [cited in Fochtmann, L. Chapter 13. Professionalism and the Heisenberg uncertainty principle In: Wear D, Aultman J, Eds. Professionalism in Medicine: Critical Perspectives. New York: Springer 2006; p. 239.

[43] Shirley J. Padgett S. Chapter 2. An analysis of the discourse of professionalism In: Wear D, Aultman J, Eds. Professionalism in Medicine: Critical Perspectives. New York: Springer 2006; p. 35.

[44] Talbott J. Chapter12. Medical professionalism in the new century: accomplishments and challenges in the future for an American medical school. In: Bhugra D, Malik A, Eds. Professionalism in Mental Healthcare: Experts, Expertise and Expectations. Cambridge: Cambridge University Press 2011.

(C) Kramer et al.; Licensee Bentham Open.

This is an open access article licensed under the terms of the Creative Commons Attribution Non-Commercial License (http://creativecommons.org/licenses/by-nc/ 3.0/) which permits unrestricted, non-commercial use, distribution and reproduction in any medium, provided the work is properly cited. 